\title{
Experimental and computational study of damage behavior of tungsten under high energy electron beam irradiation
}

\author{
Muyuan $\mathrm{Li}^{\mathrm{a}}$, Mathias Sommerer ${ }^{\mathrm{a}}$, Ewald Werner ${ }^{\mathrm{a}}$, Stefan Lampenscherf ${ }^{\mathrm{b}}$, Thorsten Steinkopf ${ }^{\mathrm{b}}$, Philipp Wolfrum $^{\mathrm{b}}$, \\ Jeong-Ha You ${ }^{\mathrm{c}, *}$ \\ ${ }^{a}$ Lehrstuhl für Werkstoffkunde und Werkstoffmechanik, Technische Universität München, Boltzmannstr.15, 85748 Garching, Germany \\ ${ }^{b}$ Siemens AG, Corporate Technology, Otto-Hahn-Ring 6, D-81730 München, Germany \\ ${ }^{c}$ Max-Planck-Institut für Plasmaphysik, Boltzmannstr.2, 85748 Garching, Germany
}

\begin{abstract}
In this work, damage behavior of tungsten under high heat flux loads was investigated both numerically and experimentally assuming a single heat pulse with duration of $0.5 \mathrm{~s}$. Finite element simulations revealed that the thermal steady state was reached within several milliseconds after the onset of a heat flux pulse and tensile residual stress was produced during cooling providing the driving force for crack growth. The crack initiation and growth simulations and $J$-integral calculation at crack tips delivered consistent results on cracking mechanism. Electron beam irradiation tests on tungsten samples were performed, which confirmed the predicted damage behavior.
\end{abstract}

Keywords: thermal shock, extended finite element method, $J$-integral, electron beam irradiation tests

\section{Introduction}

Owing to unique combination of outstanding physical properties, tungsten has been preferably deployed for various applications in cutting edge technology sectors. Tungsten possesses the highest melting point $\left(3422^{\circ} \mathrm{C}\right)$, high thermal conductivity $(173 \mathrm{~W} / \mathrm{mK}$ at room temperature), modest thermal expansion $(4.5 \mu \mathrm{m} / \mathrm{mK})$, high elastic modulus (410 GPa), extremely low sputtering rate and negligible hydrogen solubility [1]. Prominent application examples include, for instance, the armor of plasma-facing components in thermonuclear reactors [2], anode of X-ray tubes [3] and nozzle of rocket propulsion engines [4], among others. A common operational characteristic of these applications is that tungsten is exposed to extreme loading conditions, in particular, severe thermal shock loads. The tungsten materials of the three aforementioned components are repeatedly subjected to transient high heat flux loads within a short pulse duration time during normal or off-normal operation scenarios. Non-uniform fluctuation of temperature is likely to produce high thermal stress that may possibly lead to structural or functional failure of the components [5].

Tungsten behaves in a brittle manner below its ductile-to-brittle transition temperature (DBTT). Thus, tungsten can be vulnerable to brittle cracking, when it is cooled to low temperatures after the thermal shocks. This means that the base temperature of a tungsten component has a direct impact on the fracture behavior of tungsten under thermal shock, which is confirmed by the thermal shock tests [6-9]. DBTT of tungsten ranges between $400{ }^{\circ} \mathrm{C}$ and $700^{\circ} \mathrm{C}$, e.g. depending on loading rate [10]. Fracture toughness, which is a measure of resistance to fracture, is found to be smaller at lower temperatures in the fracture mechanical tests of tungsten $[10,11]$. The question raises as how to

\footnotetext{
*Corresponding author. Tel.: +49 (0)89 3299 1373; fax:+49 (0)89 32991212 .

Email address: you@ipp.mpg.de (Jeong-Ha You)
} 


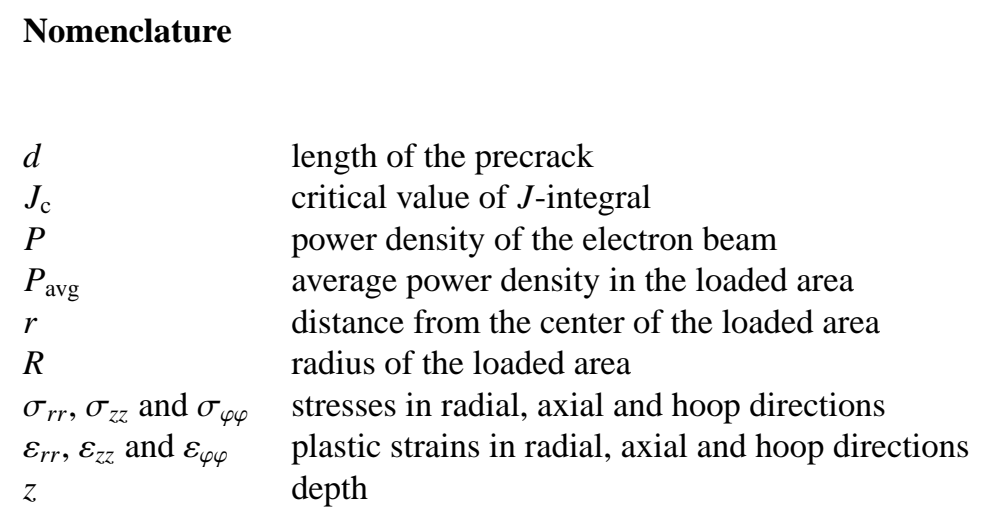

predict cracking patterns as we observe in the thermal shock tests using the data obtained in the fracture mechanical tests.

The failure process in a tungsten component under a single thermal shock load is controlled by the stress development. In the case of extreme high heat flux loads, the situation becomes more complicated due to thermal excursion in the surface layer followed by plastic flow of the softened material in this layer. During heating stage compressive thermal stress is produced in the surface layer, as thermal expansion is constrained by the colder part. On the other hand, cracking can occur only in a tensile stress state. Therefore, the experimentally observed surface cracking patterns indicate the presence of strong tensile stress developing during cooling stage. This circumstance can come about only through inelastic effects, which poses the second important question as to how plastic yield is related to evolution of tensile residual stress that provides driving force for cracking.

In this paper, these two questions are treated on the basis of computational and experimental simulation of high heat flux thermal shock loading on tungsten. The aim of the present study is two-fold: 1 . to clarify the underlying mechanism of tungsten cracking under thermal shock, and 2. to elucidate the cracking patterns of tungsten observed in extreme high heat flux operations. To this end, finite element analysis was carried out for assessment of crack tip load and for prediction of crack initiation and growth. Extended finite element method (XFEM) and virtual crack tip extension (VCE) method were employed as major tools. For experimental comparison, electron beam irradiation tests were conducted and the surface damage was characterized. To the author's knowledge, there is no previous fracture mechanics study on this topic. Related studies are found in literature which investigated stationary heat flux loading cases $[12,13]$.

In this work, we considered such thermal loading conditions that are common to both off-normal plasma operation scenarios in a thermonuclear reactor (e.g. vertical displacement events) and electron beam loading conditions in an X-ray tube.

\section{Experimental}

\subsection{Experimental settings}

Plasma facing components in future fusion devices will be subjected to intense thermal loads. To investigate these thermal loads experimentally, electron beam facilities (e.g. JUDITH, Jülich, Germany) are used frequently [8]. In $\mathrm{X}$-ray tubes, the tungsten anode is subjected to similar thermal loadings, since X-rays are generated by accelerating high energy electrons onto the anode material. The experimental facility involved in this work (as shown in Fig. 1) 
is set up at Siemens Healthcare and is used to study the failure of tungsten anodes in X-ray tubes. Tungsten samples used in our experiments were made of rolled tungsten delivered by PLANSEE AG, Austria and its purity is larger than $99.9 \mathrm{wt} \%$. The sample size was $27.5 \mathrm{~mm} \times 27.5 \mathrm{~mm} \times 3 \mathrm{~mm}$. The surface of the samples was polished before the electron beam exposure, and the final polishing was carried out using alkaline colloidal silica suspension (Logitech SF1 Polishing Fluid). The power density distribution of the electron beam at the surface of the samples was measured with an X-ray camera. The power density showed a Gaussian distribution in an oval focal spot, which has diameters of $1223 \mu \mathrm{m}$ and $271 \mu \mathrm{m}$ when the power density that less than $10 \%$ of the maximum value is neglected. For simplicity, a rectangle of $1223 \mu \mathrm{m} \times 271 \mu \mathrm{m}$ is assumed to be the loaded area. The test positions lie on a circle with a radius of $11.5 \mathrm{~mm}$, and the angle between two neighboring test positions is $17^{\circ}$, see Fig. 1. Numerical simulations have shown that, for an individual test position, the impact resulting from the electron beam exposure of the neighboring test position is negligible. The samples were loaded with single thermal loads of average power densities between $0.374 \mathrm{GW} / \mathrm{m}^{2}$ and $0.624 \mathrm{GW} / \mathrm{m}^{2}$. The average power densities were calculated by dividing the total input power rate by the loaded area and multiplying with an absorption coefficient of 0.48 . This absorption coefficient is chosen by taking account of the values $(0.46$ and 0.55$)$ found in literatures $[8,14]$ and the correlation of numerically predicted and measured temperatures in the thermal shock experiments at Siemens Healthcare. The acceleration voltage was $65 \mathrm{kV}$ and the tests were performed at room temperature. After the electron beam loading of $0.5 \mathrm{~s}$, the sample was cooled to room temperature.

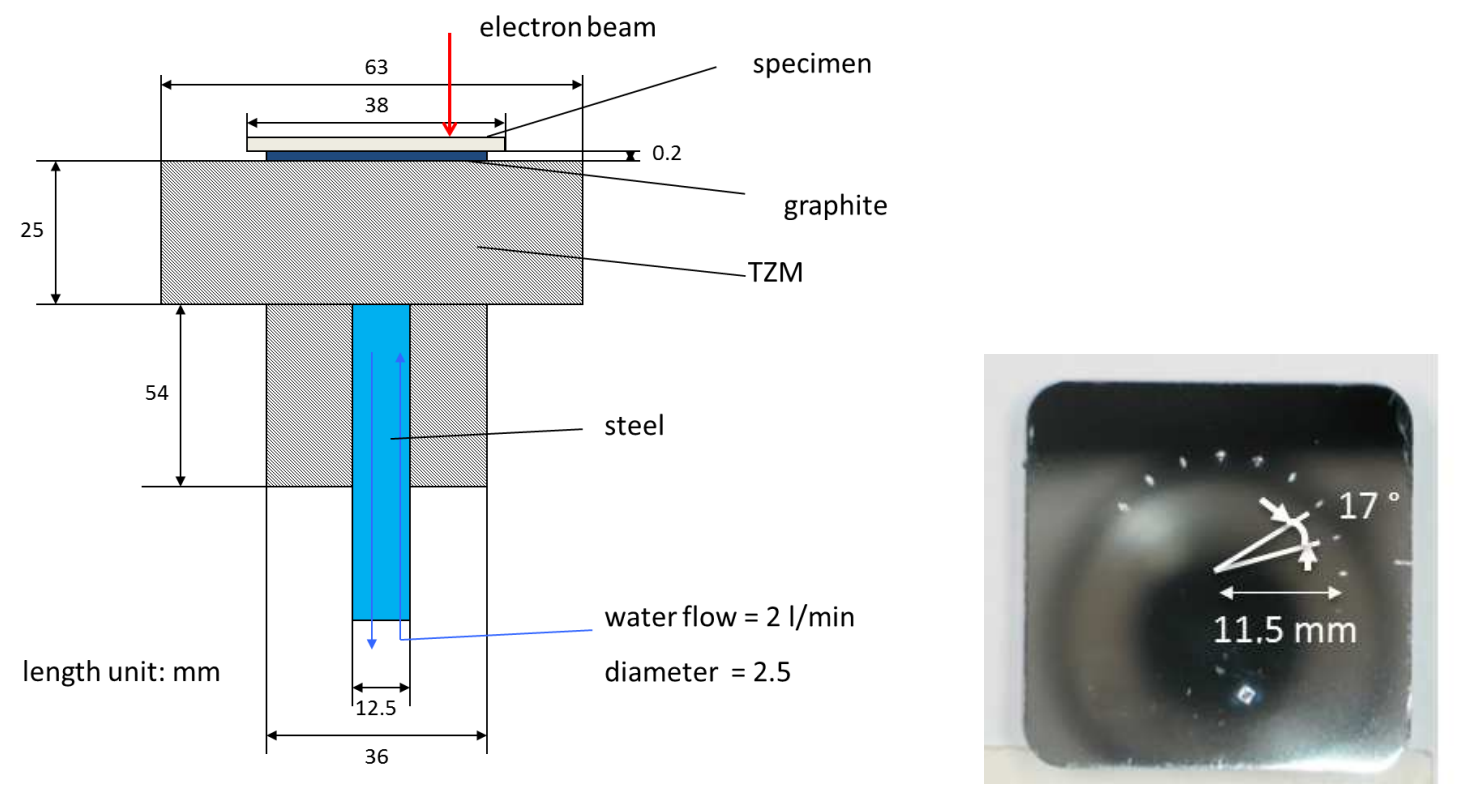

Fig. 1. Schematic drawing (left) of the cutting surface of the experimental facility at Siemens Healthcare and a top view (right) of the sample surface. TZM refers to an alloy of $0.50 \%$ titanium, $0.08 \%$ zirconium, $0.02 \%$ carbon and balance molybdenum.

\subsection{Experimental observations}

The surface roughness was measured on the tested sample using a Keyence three-dimensional Laser Scanning Microscope. Figs. 2, 3 and 4 show Laser Scanning Microscopic (LSM) images as well as out-of-plane deformation images. To enhance the visibility of the out-of-plane deformation images, a factor of 20 is applied for the deformation. The surface of the sample in the loaded area is elevated after the thermal loading. As the power density of the electron 
beam increases, the surface elevation increases. The surface elevation results from the volume compensation to the inplane plastic deformation, which is shown in the following mechanical simulations.

In LSM images, grain growth in the loaded area is observed for thermal loads of $0.5 \mathrm{GW} / \mathrm{m}^{2}$ and $0.624 \mathrm{GW} / \mathrm{m}^{2}$. The grain growth is considered to be related with recrystallization at the sample surface. The recrystallization temperature of tungsten is between $1150{ }^{\circ} \mathrm{C}$ and $1400^{\circ} \mathrm{C}$ [15]. The maximum temperatures measured for thermal loads of $0.374 \mathrm{GW} / \mathrm{m}^{2}, 0.5 \mathrm{GW} / \mathrm{m}^{2}$ and $0.624 \mathrm{GW} / \mathrm{m}^{2}$ are $1250^{\circ} \mathrm{C}, 1880^{\circ} \mathrm{C}$ and $2550^{\circ} \mathrm{C}$, respectively. The temperature was measured using a digital camera with different filters, where the brightness was correlated with the temperature. The maximum temperatures for thermal loads of $0.5 \mathrm{GW} / \mathrm{m}^{2}$ and $0.624 \mathrm{GW} / \mathrm{m}^{2}$ are much higher than the recrystallization temperature of tungsten. As a result, the grain growth is observed in the loaded area, although the loading only lasts for $0.5 \mathrm{~s}$.

For a thermal shock load of $0.374 \mathrm{GW} / \mathrm{m}^{2}$, no crack is observed at the sample surface. Tiny cracks occur under a thermal shock load of $0.5 \mathrm{GW} / \mathrm{m}^{2}$. For a thermal shock load of $0.624 \mathrm{GW} / \mathrm{m}^{2}$, cracks occur. For a better view of cracks, an image is taken with back-scattered electrons (BSE), see Fig. 5. The BSE image shows that after $0.5 \mathrm{~s}$ thermal loading with $0.624 \mathrm{GW} / \mathrm{m}^{2}$, a clearly grain growth occurs in the loaded area, and there are cracks initiated along the grain boundaries.
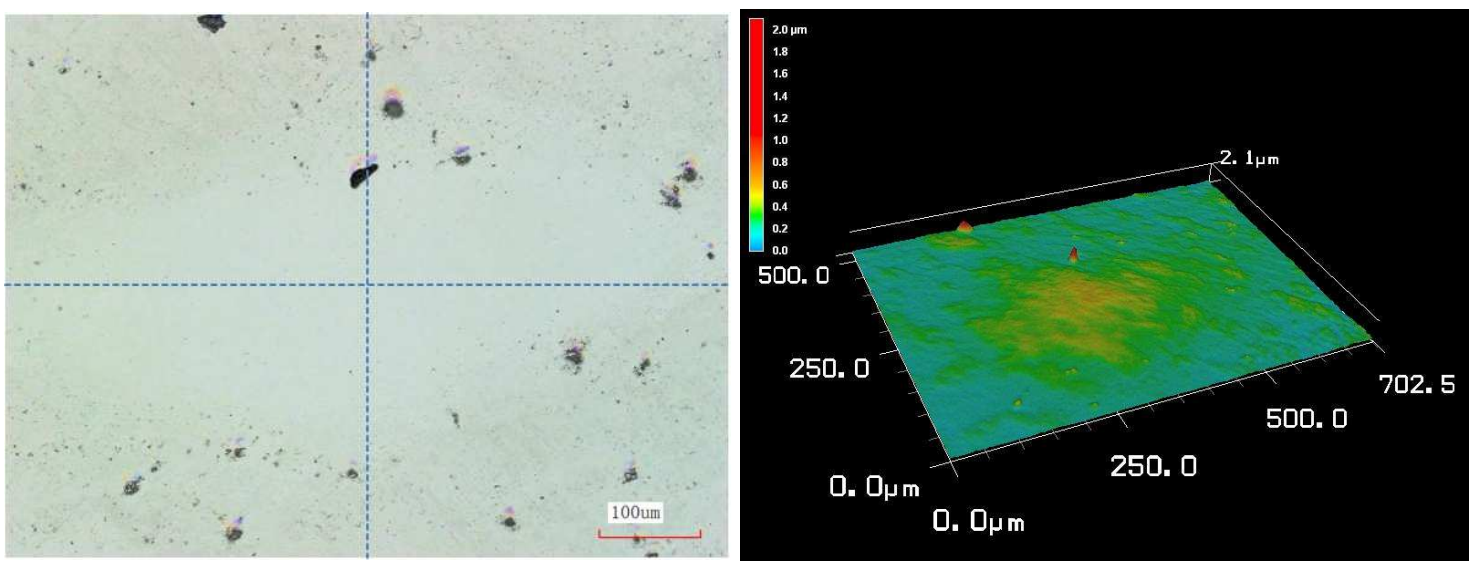

Fig. 2. LSM and out-of-plane deformation images of the sample surface for a thermal shock load of $0.374 \mathrm{GW} / \mathrm{m}^{2}$.

\section{FE model}

\subsection{Geometry and FE mesh}

In the single thermal shock experiments, the cooling and holding devices below the sample do not play a critical role for the material behavior near the sample's top surface, as the temperature at the bottom of the sample is not influenced significantly by the single thermal shock. Therefore, in the simulation, the cooling and holding devices below the sample are not modeled. For simplicity, a circular loaded area was considered instead of the rectangular focal spot. The sample was assumed to be a disk with a thickness of $3 \mathrm{~mm}$, and the loading was assumed in the central part of the top surface. The radius of the circular loaded area was $324 \mu \mathrm{m}$ to match the rectangular focal spot of the electron beam. The radius of the disk was set large enough $(8 \mathrm{~mm})$ so that the electron beam loading can be treated as a localized loading. The simplifications allow for a two-dimensional axisymmetric model. Compared to a three-dimensional model, a two-dimensional model reduces computational effort significantly and avoids convergence difficulties. For validation, a three-dimensional FE simulation with a rectangular loaded area was performed. Fig. 6 

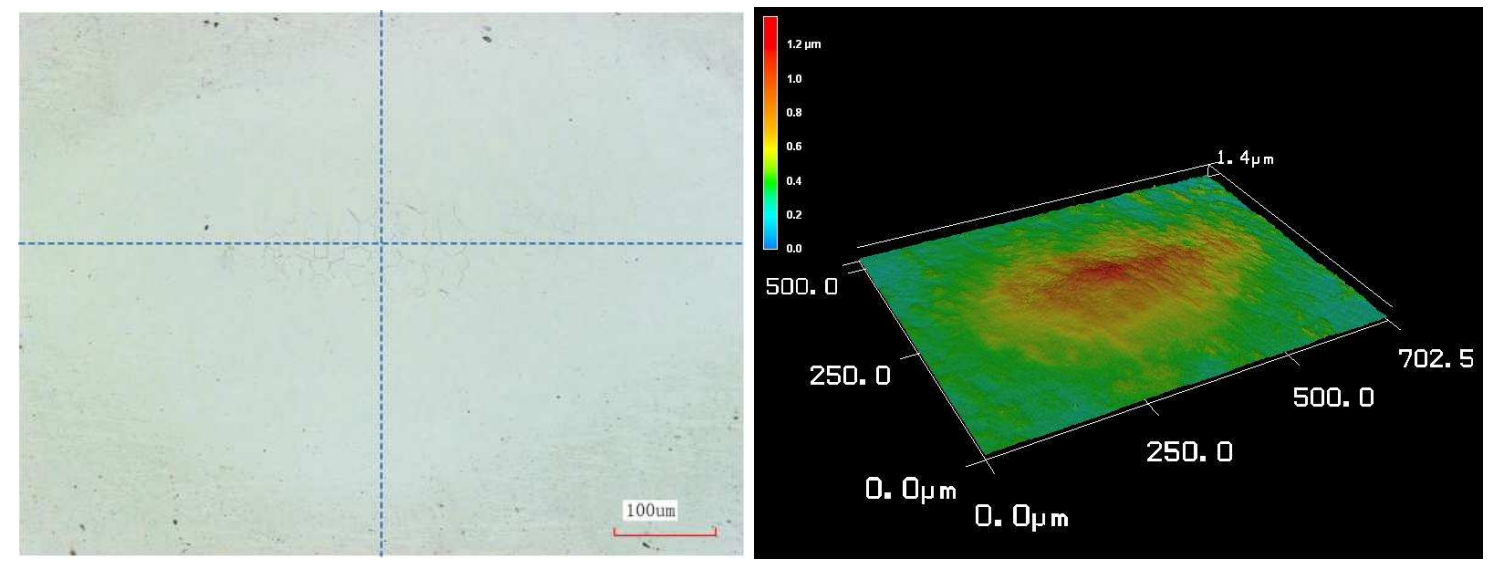

Fig. 3. LSM and out-of-plane deformation images of the sample surface for a thermal shock load of $0.5 \mathrm{GW} / \mathrm{m}^{2}$.
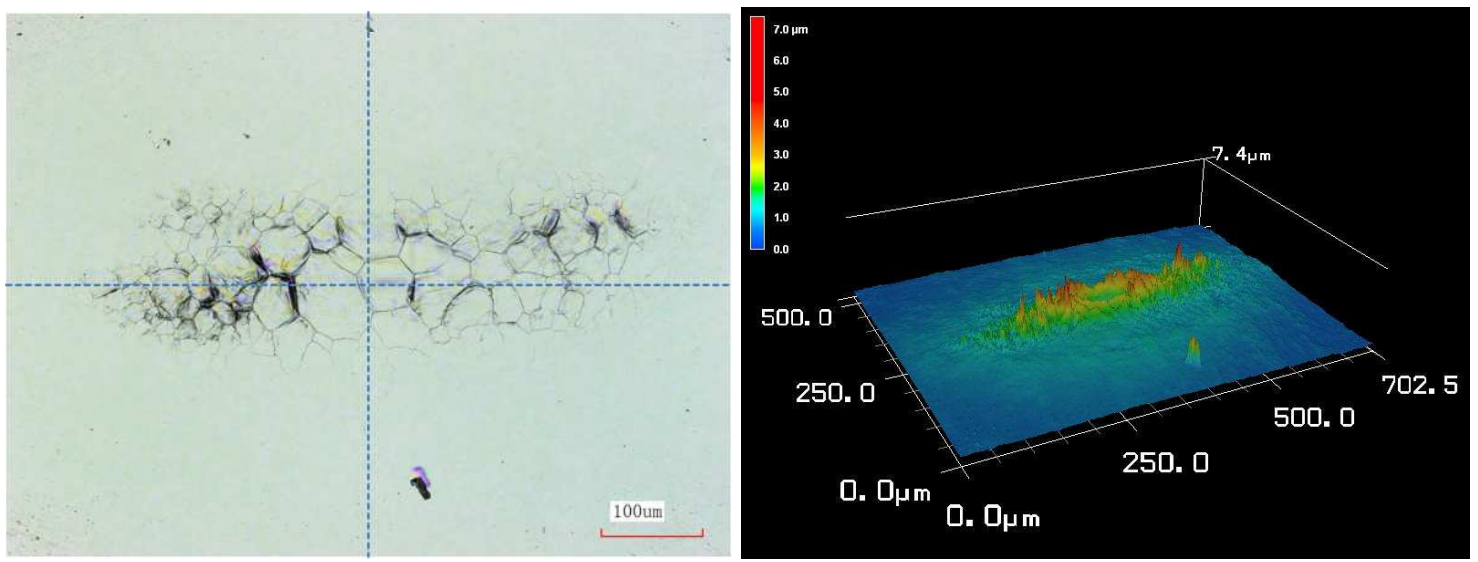

Fig. 4. LSM and out-of-plane deformation images of the sample surface for a thermal shock load of with $0.624 \mathrm{GW} / \mathrm{m}^{2}$.

shows the temperature predicted by the two-dimensional (axisymmetric) and the three dimensional models (a quarter is modeled due to symmetry). The temperature along the surface calculated by the two-dimensional model can represent a general case between two extreme cases in the three-dimensional simulations (along the long and short axes). The discrepancy between the temperatures along the depth predicted by the two-dimensional and the threedimensional models can be neglected. Therefore the temperature calculated by the two-dimensional model can capture the main feature of the temperature distribution predicted by the three-dimensional model.

The simulations were performed with the commercial FEM tool ABAQUS [16]. A four-node axisymmetric quadrilateral element was used for the thermal and mechanical simulations. In total, there were 11598 elements. In order to obtain accurate results in the domain under the thermal shock loads, a finer FE mesh with an element edge size of $4 \mu \mathrm{m}$ is used in this area, see Fig. 7.

\subsection{Loading and boundary conditions}

In the simulations, the electron beam was modeled as a surface heat flux load. The power density of the electron beam, $P$, was Gaussian distributed at the sample surface, as described by equation (1), 


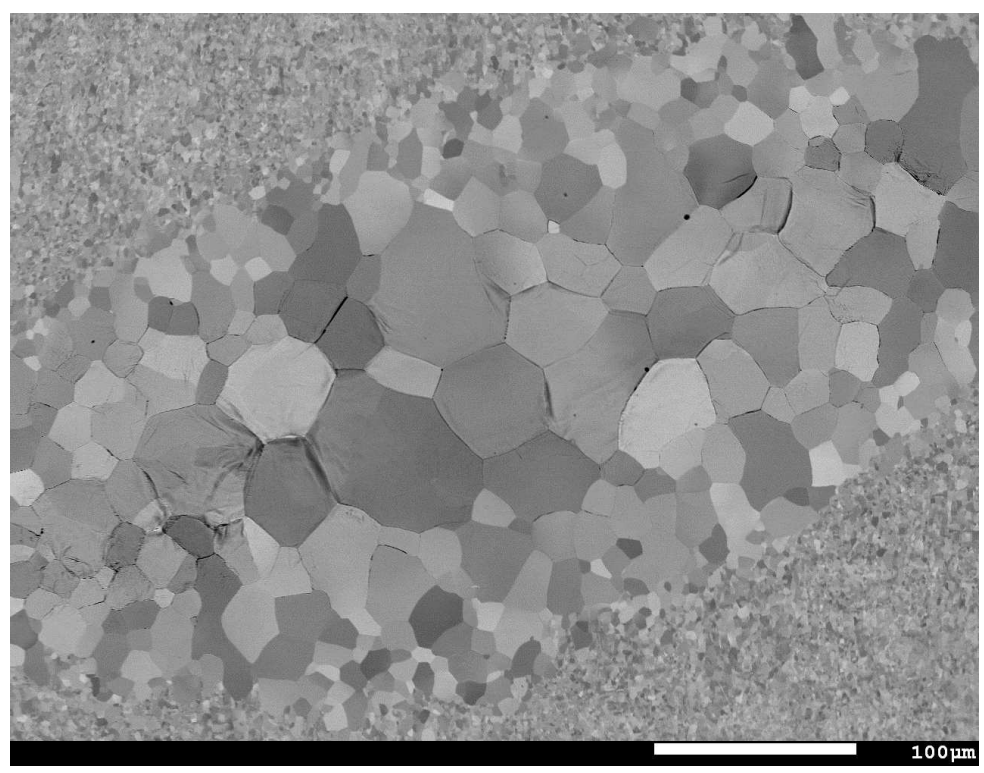

Fig. 5. A BSE image of the sample surface for a thermal shock load of with $0.624 \mathrm{GW} / \mathrm{m}^{2}$.

$$
P=2.2061 P_{\mathrm{avg}} e^{-\frac{2 r^{2}}{R^{2}}}
$$

where $P_{\text {avg }}$ is the average power density in the loaded area, $r$ is the distance from the center of the loaded area and $R$ is radius of the loaded area, see Fig. 7. This distribution is scaled from the measured power density distribution along the long axis of the oval focal spot. The small amount of energy distributed outside the loaded area is neglected in the simulations.

The average power density in the loaded area ranged from $0.374 \mathrm{GW} / \mathrm{m}^{2}$ to $0.624 \mathrm{GW} / \mathrm{m}^{2}$. The loading duration was $0.5 \mathrm{~s}$. As cooling devices do not have much impact on the temperatures near the top surface of the tungsten sample, a convective boundary condition was assumed at the bottom surface for the sake of simplicity.

\section{Materials}

The simulations in this work were performed in a continuum mechanics framework, and the material was assumed to be homogenous and isotropic. In the simulations, mechanical properties, such as Young's modulus and yield stress and thermal material parameters of tungsten, such as thermal conductivity, coefficient of thermal expansion and specific heat, refer to the data presented in literatures [17, 18]. Mechanical and thermal material parameters of tungsten at selected temperatures are listed in Tables 1 and 2.

The values of yield stress and ultimate tensile strength of tungsten are nearly the same [17]. Therefore, tungsten is assumed to behave elastic-ideally plastic in all simulations.

\section{Thermo-mechanical simulations}

For the numerical study in this work, the heat transfer problem was solved first. After that, its solution was read into the corresponding mechanical simulation as a predefined temperature field. 

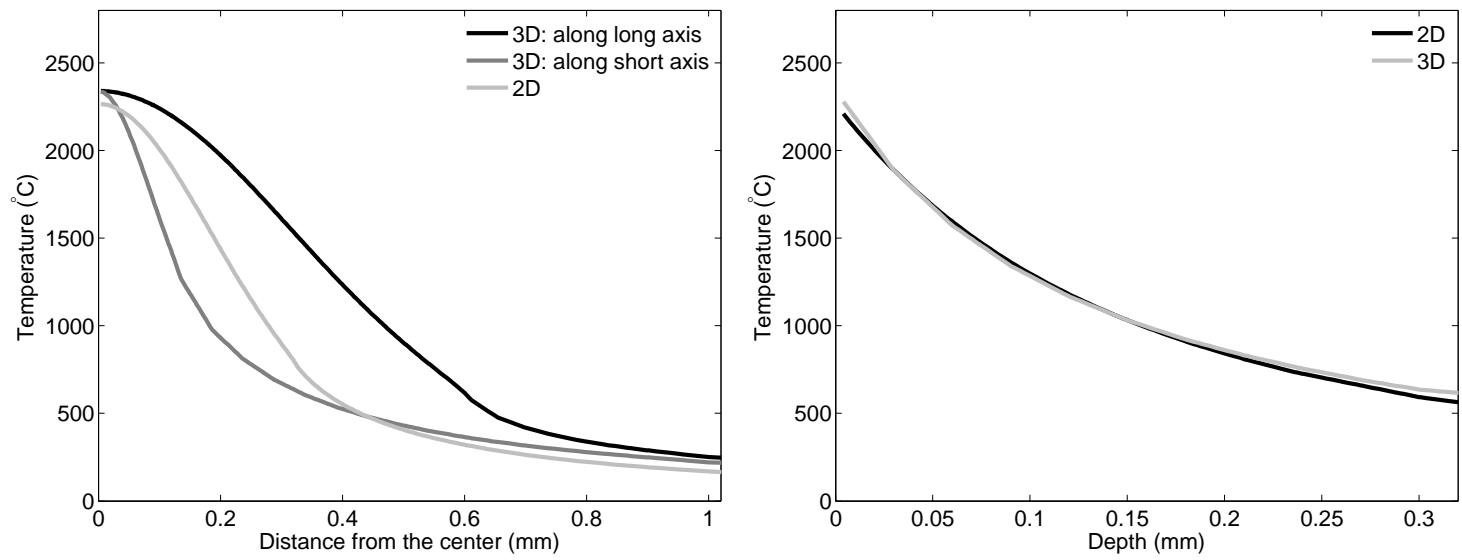

Fig. 6. Temperature along the surface (left) and the depth (right) for a thermal shock load of $0.624 \mathrm{GW} / \mathrm{m}^{2}$ for the two-dimensional and the three-dimensional simulations.

Table. 1. Mechanical material parameters of tungsten at selected temperatures [17]

\begin{tabular}{ccc}
\hline \hline Temperature $\left({ }^{\circ} \mathrm{C}\right)$ & Young's modulus $(\mathrm{GPa})$ & Yield stress $(\mathrm{MPa})^{\mathrm{a}}$ \\
\hline 20 & 399 & infinite $^{a}$ \\
200 & 391 & 1221 \\
600 & 375 & 724 \\
1000 & 356 & 467 \\
1600 & 321 & 64 \\
2000 & 278 & 42 \\
\hline
\end{tabular}

${ }^{a}$ No value is reported in [17]. Here, it is assumed that tungsten behaves purely elastic at this temperature.

\subsection{Thermal simulations}

The temperature field at the end of heating is shown in Fig. 8 for a thermal shock load of $0.624 \mathrm{GW} / \mathrm{m}^{2}$. High temperature only occurs in the loaded area. At a position of approximately $1 \mathrm{~mm}$ away from the loading center, the temperature is below $200{ }^{\circ} \mathrm{C}$ at the end of heating. The temperatures at the surface and along the axis of symmetry are shown in Figs. 9 and 10 for thermal shock loads of different power densities. The temperature increases as the power density increases and the temperature decreases as the distance from the center of the loaded area increases. For all three power densities, the temperature during heating is above DBTT in most parts of the loaded area. Fig. 11 shows the temperature at the surface as a function of time for a thermal shock load of $0.624 \mathrm{GW} / \mathrm{m}^{2}$. The temperature in the center of the loaded area increases from room temperature to $2170{ }^{\circ} \mathrm{C}$ within $0.01 \mathrm{~s}$. During the remaining heating time $(0.49 \mathrm{~s})$, it increases further by less than $100^{\circ} \mathrm{C}$, indicating that a quasi-steady-state is reached after the first few milliseconds. After heating, the temperature gradient in the loaded area is drastically reduced within $0.002 \mathrm{~s}$, as shown in Fig. 11. The numerical findings are in accordance with the analytical solutions reported in [19] for the one-dimensional heat conduction problem encountered when cooling down a sample of which the infinite surface is heated by a heat source of finite size prior to cooling.

\subsection{Mechanical simulations}

\subsubsection{Plastic strain fields}

When the material is subjected to high temperatures and temperature gradients, plastic strains cannot be avoided. Fig. 12 gives an overview of the plastic strain fields for a thermal shock load of $0.624 \mathrm{GW} / \mathrm{m}^{2}$. During heating, the 


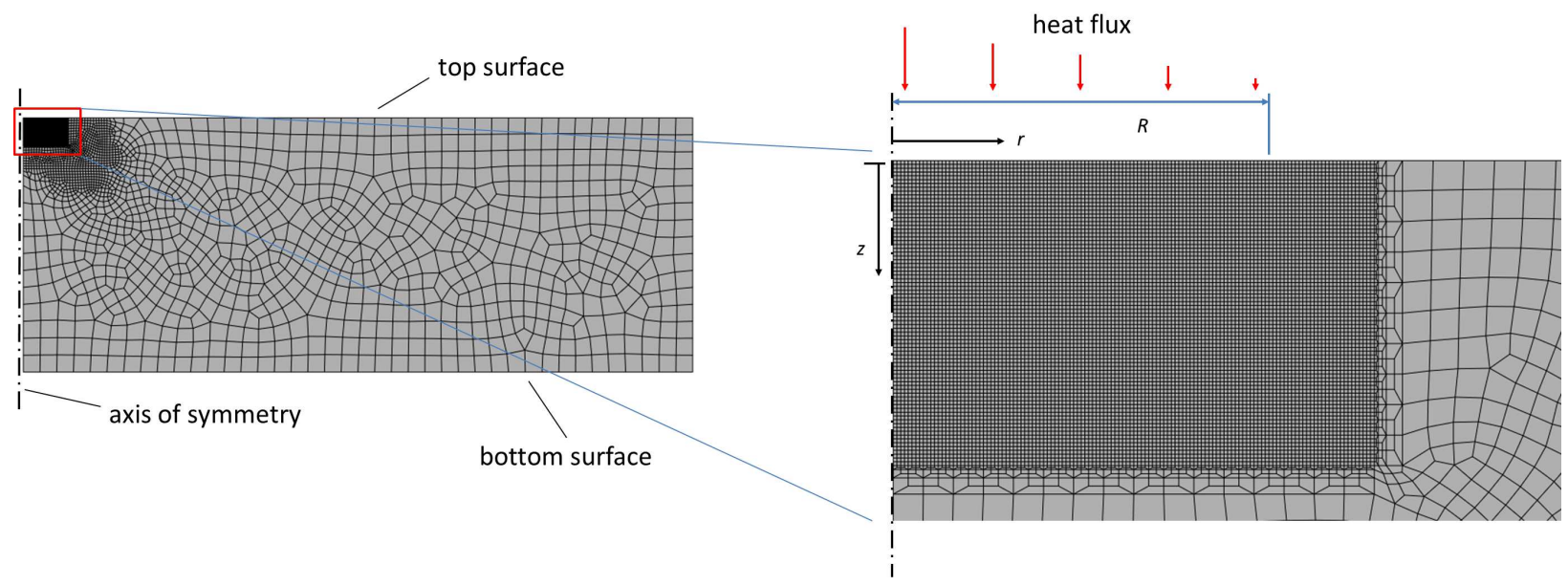

Fig. 7. FE mesh of the two-dimensional axisymmetric model and finer mesh in the domain beneath the thermal shock loads. The axisymmetric boundary condition is applied on the left edge. $R$ is the radius of the loaded area. $r$ is the distance from the center of the loaded area. $z$ denotes depth.

Table. 2. Thermal material parameters of tungsten at selected temperatures [18]

\begin{tabular}{ccccc}
\hline \hline $\begin{array}{c}\text { Temperature } \\
\left({ }^{\circ} \mathrm{C}\right)\end{array}$ & $\begin{array}{c}\text { Thermal conductivity } \\
(\mathrm{W} / \mathrm{mK})\end{array}$ & $\begin{array}{c}\text { Density } \\
\left(\mathrm{kg} / \mathrm{m}^{3}\right)\end{array}$ & $\begin{array}{c}\text { Specific heat } \\
(\mathrm{J} / \mathrm{kgK})\end{array}$ & $\begin{array}{c}\text { Coefficient of thermal expansion } \\
\left(10^{-6} / \mathrm{K}\right)\end{array}$ \\
\hline 27 & 176 & 19299 & 133 & 4.74 \\
927 & 114 & 19051 & 155 & 5.06 \\
1927 & 99 & 18725 & 180 & 6.77 \\
2727 & 92 & 18379 & 218 & 9.19 \\
\hline
\end{tabular}

thermal expansion is largely constrained by the cold bulk material outside the loaded area. As a result, plastic strain in radial direction is generated by compressive stress during the loading time. In the cooling phase, plastic strain in radial direction is generated by tensile stress due to the shrinking of the materials. However, the plastic strain in radial direction generated during cooling cannot counterbalance the plastic strain in radial direction generated during heating. The remaining plastic strain in radial direction leads to a residual stress field at the end of cooling. The plastic strains in the hoop and the radial directions are very similar. In axial direction, the plastic strain can be estimated under the assumption that the plastic flow usually takes place without change in volume, corresponding to a Poisson's ratio of 1/2. As a result, there is two times as much plastic strain in axial direction as there is in radial direction, see Fig. 13.

Fig. 14 shows the surface plastic strain in radial direction after $0.5 \mathrm{~s}, 0.502 \mathrm{~s}$ and $16 \mathrm{~s}$ for a thermal shock load of $0.624 \mathrm{GW} / \mathrm{m}^{2}$. Plastic strain in radial direction is negative at the end of heating due to the constraint of the cold bulk material surrounding the loaded area. After heating stops, a large reduction of the magnitude of the surface plastic strain in radial direction takes place within $0.002 \mathrm{~s}$, which indicates that the material in the loaded area is in a tensile state. The magnitude of the plastic strain in radial direction in the center of the loaded area is significantly more reduced than at other locations. Within $0.002 \mathrm{~s}$ after heating stops, almost no further plastic strain in radial direction is generated, as the plastic strains are almost identical for $0.502 \mathrm{~s}$ and $16 \mathrm{~s}$. In Fig. 15, plastic strain in radial direction at different depths is shown at the end of cooling for a thermal shock load with $0.624 \mathrm{GW} / \mathrm{m}^{2}$. In the center of the loaded area, the magnitude of plastic strain in radial direction at the surface is smaller than at a depth of $0.032 \mathrm{~mm}$, while it is larger at the surface at the end of heating, see Fig. 12. This indicates that less plastic strain in radial direction is 


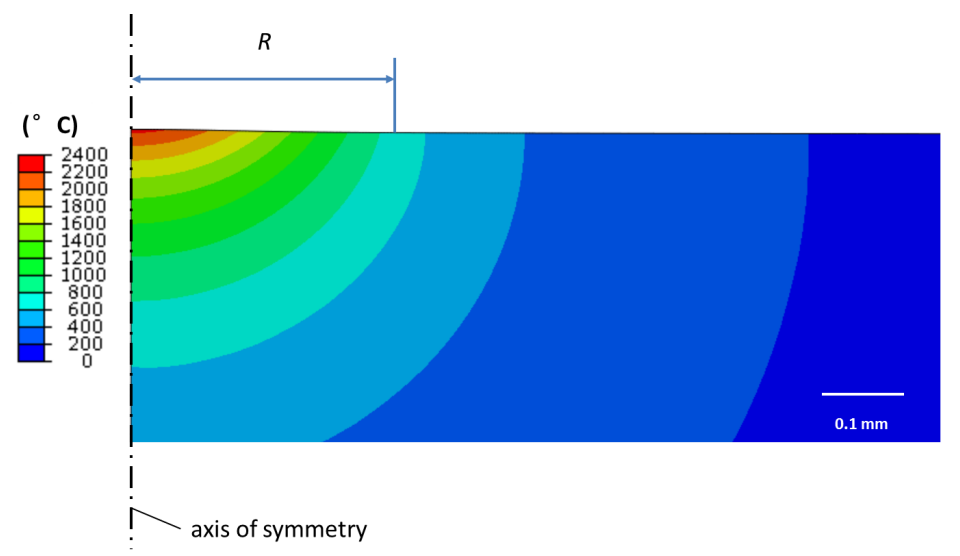

Fig. 8. Temperature field at the end of heating for a thermal shock load of $0.624 \mathrm{GW} / \mathrm{m}^{2}$.

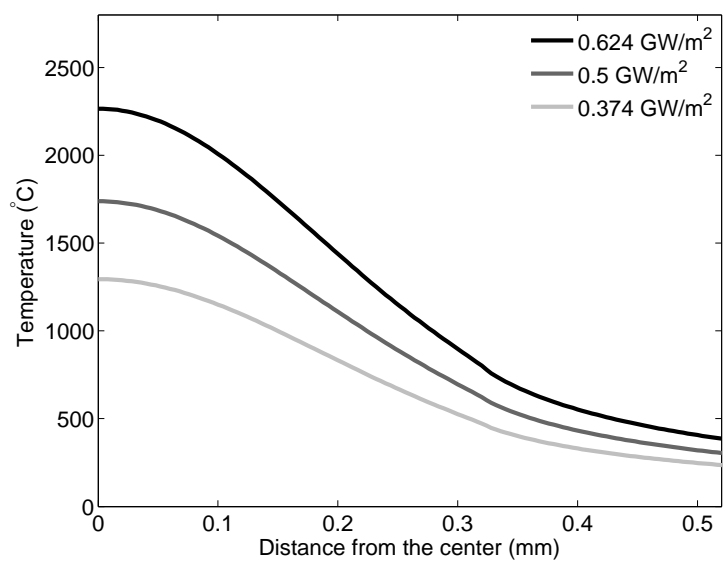

Fig. 9. Temperature at the surface at the end of heating for thermal shock loads of different power densities.

generated during cooling at a depth of $0.032 \mathrm{~mm}$ than there is at the surface.

The influence of the power density on the surface plastic strain in radial direction is shown in Fig. 16. The size of the surface plastic zone increases, as the power density increases. Although a larger power density leads to a larger magnitude of plastic strain in radial direction in the center of the loaded area during heating, the plastic strain in radial direction generated during cooling is larger as well. Surface plastic strains in radial direction in the center of the loaded area are almost identical at the end of cooling for thermal loads of $0.624 \mathrm{GW} / \mathrm{m}^{2}$ and $0.5 \mathrm{GW} / \mathrm{m}^{2}$. However, at a depth of $0.08 \mathrm{~mm}$, the plastic strains in radial direction are different, see Fig. 17. The magnitude of plastic strain is larger for a larger power density.

\subsubsection{Stress fields}

Fig. 18 shows an overview of stress fields. During heating compressive stresses are generated, and stresses are limited by the low yield stress of tungsten at high temperatures. After the sample has cooled down, residual tensile stress is generated due to the plastic strain field. There are two critical locations at which a concentration of residual stress in radial direction can be observed: firstly, the region right below the loading center; secondly, the region close to the edge of the loaded area at the surface, see the field of stress in radial direction at the end of cooling in 


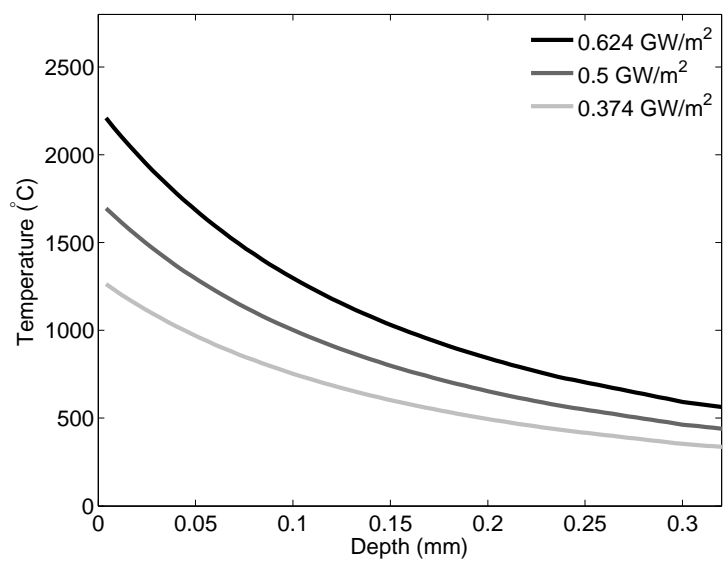

Fig. 10. Temperature along the axis of symmetry at the end of heating for thermal shock loads of different power densities.

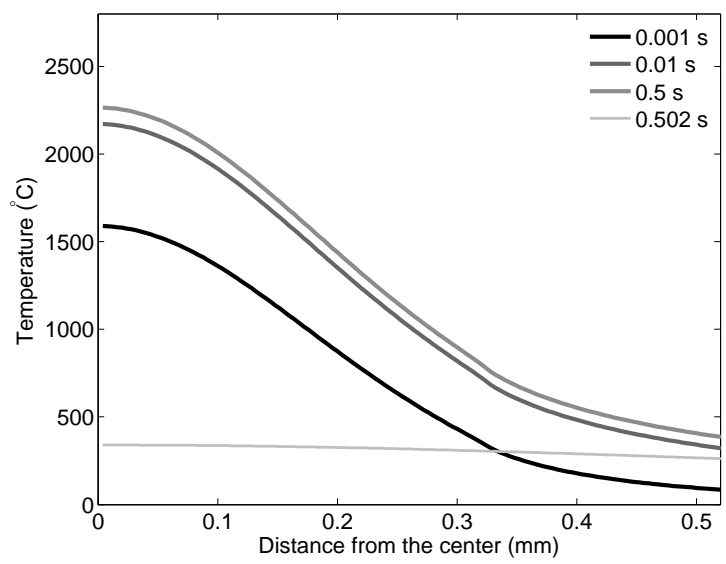

Fig. 11. Temperature at the surface at various times for a thermal shock load of $0.624 \mathrm{GW} / \mathrm{m}^{2}$. The loading duration is $0.5 \mathrm{~s}$.

Fig. 18. The stress in hoop direction behaves similarly to the stress in radial direction except that there is no stress concentration near the edge of the loaded area at the surface. Stress in axial direction is negligible compared to the radial or hoop stresses.

In Fig. 19 the evolution of surface stress in radial direction is shown for a thermal shock load of $0.624 \mathrm{GW} / \mathrm{m}^{2}$. The surface stress in radial direction is compressive during heating and tensile during cooling. At the end of cooling, the stress in radial direction changes from tensile to compressive, as depth increases (see Fig. 20). This is due to the bending effect caused by the stress profile in depth direction.

The influence of power density on the surface stress in radial direction is shown in Fig. 21. The maximum surface stress in radial direction and the distance between the center of the loaded area and the position where the maximum surface stress in radial direction occurs both increase as the power density increases. In the center of the loaded area, however, an increase in power density leads to smaller stress in radial direction. At a depth of $0.08 \mathrm{~mm}$, the influence of power density on stress is more significant, see Fig. 22. Stress is larger for a larger power density. 

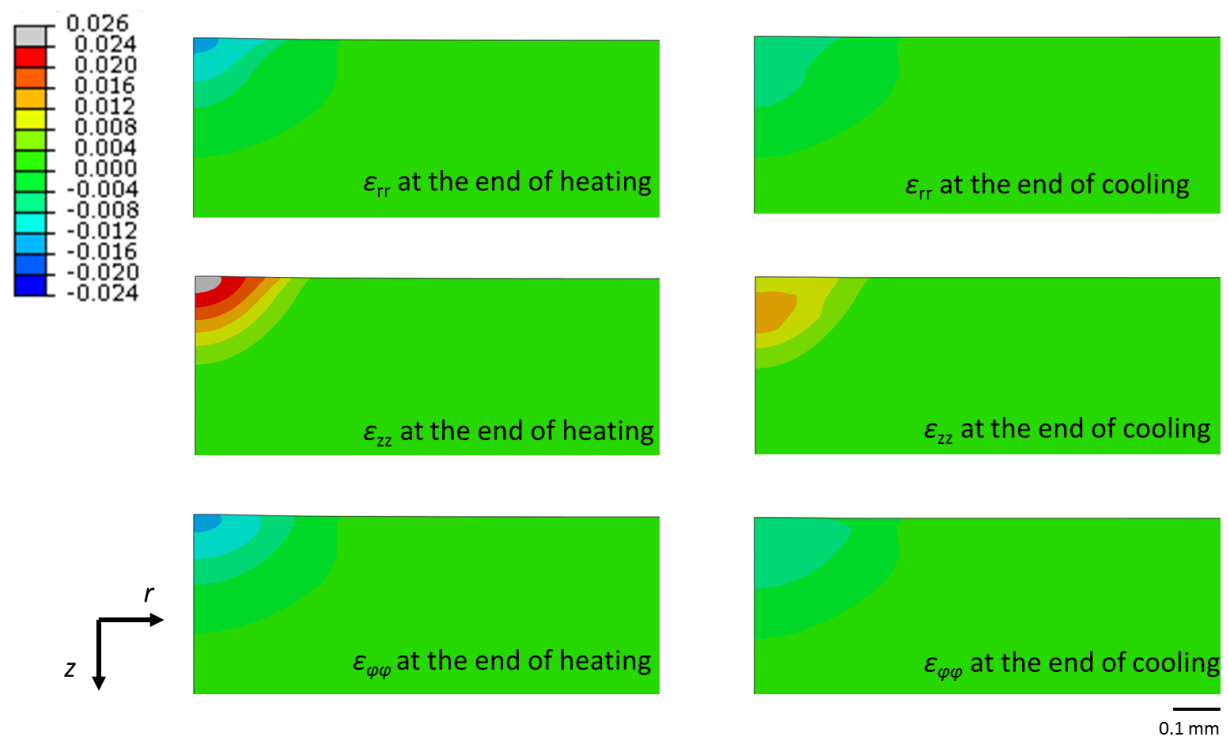

Fig. 12. Plastic strain fields for a thermal shock load of $0.624 \mathrm{GW} / \mathrm{m}^{2} . \varepsilon_{r r}, \varepsilon_{z z}$ and $\varepsilon_{\varphi \varphi}$ are the plastic strains in radial, axial and hoop directions.

\section{Fracture analysis}

Cracks at the surface of the tungsten armors can rapidly propagate into the tungsten component and lead to a loss of functionality, which shortens the life time of the component significantly. In this work, both XFEM and the FEM-based VCE method are used to conduct a fracture analysis. With XFEM, one is able to predict crack initiation and propagation, while the FEM-based VCE method can be used to calculate fracture mechanical parameters.

\subsection{XFEM simulation}

With XFEM, the FE mesh does not need to be updated to track the crack path, which is considered to be the biggest advantage of XFEM over the conventional FEM. To simulate crack initiation and propagation, a maximum principal stress criterion (MPS) for crack initiation and an energy based damage evolution law for crack growth are applied. Hence, the assumption of precracks is not needed in the XFEM simulations. Once the principal stress exceeds its maximum allowable value, a crack is initiated. At the same time, the cohesive stiffness in the elements, in which crack formation occurs, is degraded. The cohesive stiffness degradation is described by the energy based damage evolution law. If the energy dissipation associated with crack extension is larger than the fracture energy, the cohesive stiffness becomes zero, and the crack is completely opened. The value of ultimate tensile strength can in principle be used for the MPS. The ultimate tensile strength of tungsten around its DBTT $\left(400^{\circ} \mathrm{C}-700^{\circ} \mathrm{C}\right)$ is about $900 \mathrm{MPa}$ $700 \mathrm{MPa}$ [17]. Considering that crack formation is mainly due to the brittleness of tungsten below DBTT, the MPS is defined to be $900 \mathrm{MPa}$. For the fracture energy used for damage evolution, $0.25 \mathrm{~mJ} / \mathrm{mm}^{2}$ is used, which is transferred from the fracture toughness obtained from the test at $400^{\circ} \mathrm{C}$ performed by Gludovatz et al. [11] based on linear elastic fracture mechanics.

The XFEM predictions are collected in Figs. 23, 24 and 25. The quantity STATUSXFEM characterizes damage evolution. A value of 1.0 characterizes an opened crack. Positive values smaller than 1.0 stand for cracks that require additional energy to be opened. For thermal shock load of $0.374 \mathrm{GW} / \mathrm{m}^{2}$, initiation of a single crack that requires additional energy to be opened is predicted, which indicates that this loading is not critical for cracking, see Fig. 23. 


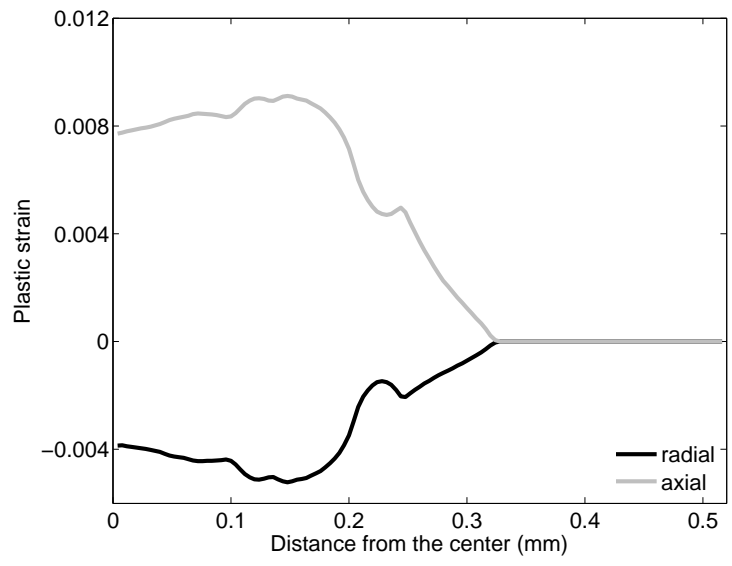

Fig. 13. Surface plastic strain in radial and axial directions at the end of cooling for a thermal shock load of $0.624 \mathrm{GW} / \mathrm{m}^{2}$.

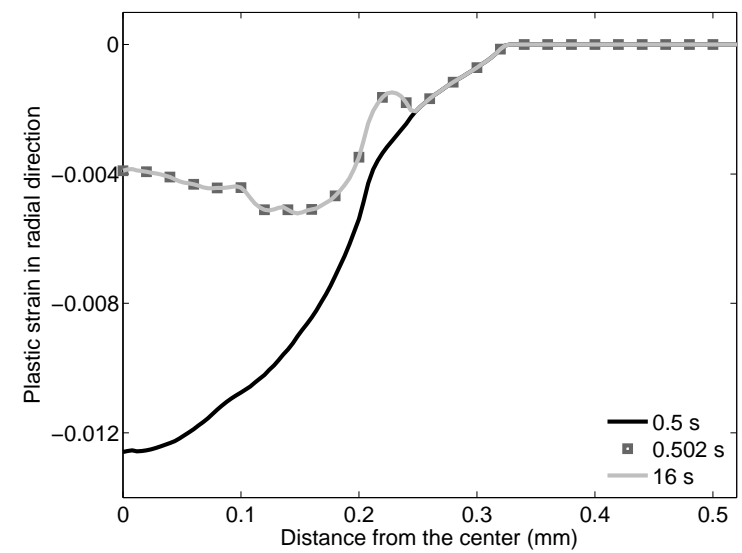

Fig. 14. Surface plastic strain in radial direction at various times for a thermal shock load of $0.624 \mathrm{GW} / \mathrm{m}^{2}$.

For a thermal shock load of $0.5 \mathrm{GW} / \mathrm{m}^{2}$, several cracks are initiated (Fig. 24), but they need additional energy to be opened. The multiple crack initiations, which are close to each other, result in a degradation of the cohesive stiffness in the corresponding area. However, the densely distributed cracks will rarely occur in reality, since intergranular cracking is more likely to occur due to the weaknesses of the grain boundaries. For intergranular cracking the distance between two cracks is at least the size of a grain. When the distance between the cracks is larger, the energy dissipation associated with crack extension will also be larger, which indicates that opened cracks may occur for the loading of $0.5 \mathrm{GW} / \mathrm{m}^{2}$. In Fig. 25, opened cracks are found for a thermal shock load of $0.624 \mathrm{GW} / \mathrm{m}^{2}$. Compared to the tensile stress at the surface, the tensile stress below the surface is larger (as shown in Fig. 18). As a result, cracks are initiated below the surface. This effect leads to impurities below the surface, possibly as a result of the fabrication process, critical for cracking. 


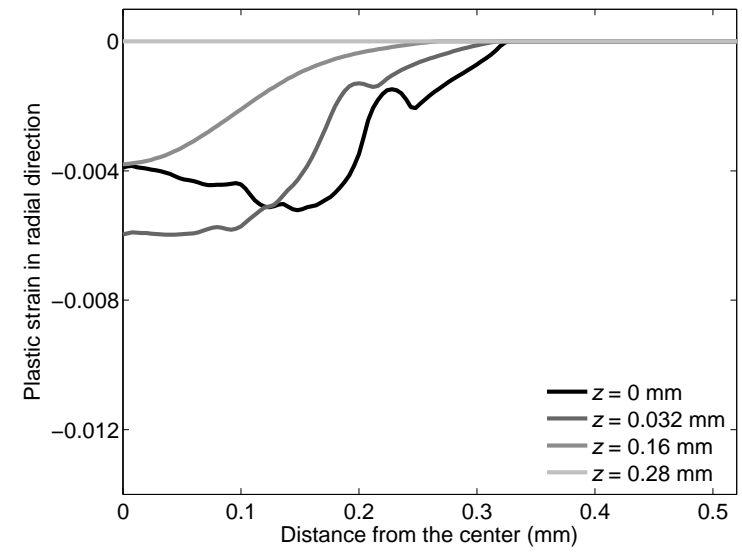

Fig. 15. Plastic strain in radial direction at different depths at the end of cooling for a thermal shock load of $0.624 \mathrm{GW} / \mathrm{m}^{2}$.

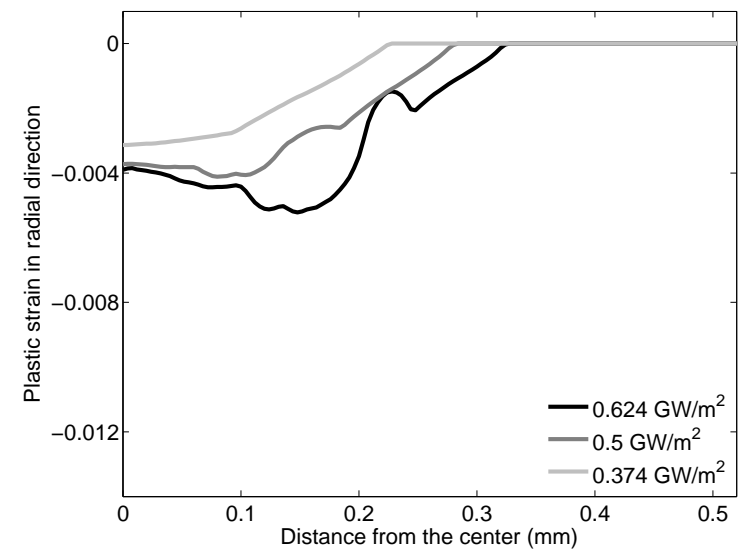

Fig. 16. Surface plastic strain in radial direction at the end of cooling for thermal shock loads of different power densities.

\subsection{J-integral calculation}

The $J$-integral [20] is a useful quantity for the analysis of the mechanical fields near crack tips. In this work, the $J$-integral was calculated using the FEM-based VCE method with the axisymmetric model ${ }^{1}$. The $J$-integral is numerically attractive, since it can be evaluated by a path independent contour integral. To compute the contour integrals, the domain integral method is used, which is quite robust in the sense that accurate contour integral estimates are usually obtained even with quite coarse meshes. The $J$-integral in this work is calculated at the end of cooling, when the material behaves purely elastic. If plasticity occurs, the $J$-integral calculation is also possible by describing the elasto-plastic material behavior as an "equivalent elastic material" [16]. However, the residual stress influence must be considered, otherwise the $J$-integral will not be path-independent. A path-independent $J$-integral can be obtained when the residual stress field is treated as an initial strain field [21], which has been implemented in ABAQUS [16]. The criterion for crack propagation is defined as follows: As the $J$-integral reaches its critical value $\left(J_{c}\right)$, unstable

\footnotetext{
${ }^{1}$ The $J$-integral can be calculated with XFEM as well, however, currently only for first-order or second-order tetrahedron and first-order brick elements for three-dimensional models in ABAQUS XFEM code [16], which does not fit to the two dimensional model set up in this work.
} 


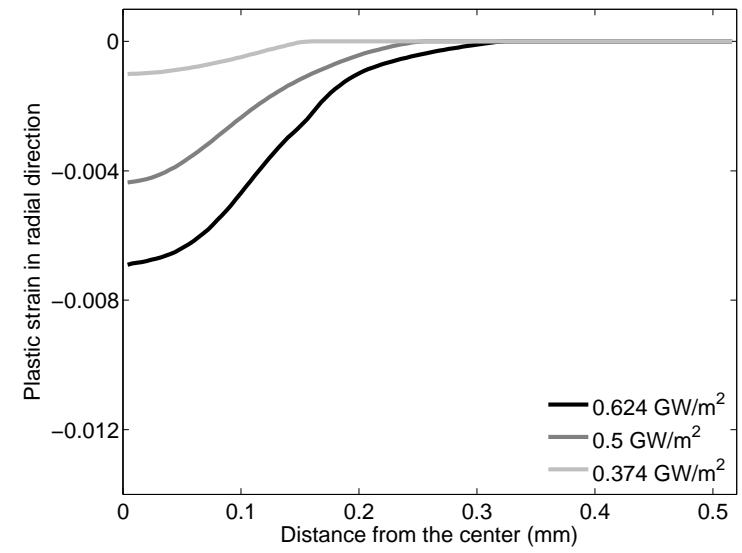

Fig. 17. Plastic strain in radial direction at a depth of $0.08 \mathrm{~mm}$ at the end of cooling for thermal shock loads of different power densities.

fracture sets in, and cracks can propagate. The critical value of the $J$-integral is defined to be the same as the fracture energy.

In the XFEM calculations, only cracks perpendicular to the top surface are found. Therefore, in this work, only $J$-integrals for precracks perpendicular to the top surface are computed at the end of cooling. The direction of the virtual crack tip extension is defined pointing into the sample. Length and location of precracks (see Fig. 26) are the variables of a parametric study. To avoid influence from other cracks, only one precrack is allowed in each simulation, where the growth of the precrack is not possible.

Fig. 27 shows the calculated $J$-integrals as a function of crack length and location for different thermal shock loads. In general, the $J$-integrals first increase as the crack length increases. Then, after reaching a maximum, they decrease again. . For a thermal shock load of $0.374 \mathrm{GW} / \mathrm{m}^{2}, J$-integrals are much smaller than $J_{\mathrm{c}}$, and no crack growth will occur. For a thermal shock load of $0.5 \mathrm{GW} / \mathrm{m}^{2}$, in the central part of the loaded area $(r=0.041,0.162 \mathrm{~mm})$ the $J$-integral for a precrack which is shorter than $8 \mu \mathrm{m}$, is smaller than $J_{\mathrm{c}}$, while it is larger than $J_{\mathrm{c}}$ for a precrack longer than $16 \mu \mathrm{m}$. Since the grain boundaries are more vulnerable than the grain interior, and hence assuming that the initial defect can grow more easily along the interface between two grains into a crack of $16 \mu \mathrm{m}$ perpendicular to the surface, further crack growth can occur according to the $J$-integral calculation. For a thermal shock load of $0.624 \mathrm{GW} / \mathrm{m}^{2}$, nearly all $J$-integrals are larger than $J_{\mathrm{c}}$ in the central part of the loaded area. Crack propagation is very likely to occur. However, the $J$-integral is smaller than $J_{\mathrm{c}}$, as the crack length is larger than $0.15 \mathrm{~mm}$, which indicates that this crack cannot become longer than $0.15 \mathrm{~mm}$. The crack occurrence obtained from the $J$-integral calculations generally coincides with XFEM predictions.

\section{Comparison of experimental and simulation results}

\subsection{Maximum temperature and cracking occurrence}

Fig. 28 shows a comparison of the maximum temperatures measured in the experiments and calculated in the corresponding simulations. The maximum temperature is linearly dependent on the power density. For a thermal shock load of $0.374 \mathrm{GW} / \mathrm{m}^{2}$, the simulation result coincides with the measured value quite well. However, the deviation between the simulation results and the measured values is obvious for a thermal shock load of $0.624 \mathrm{GW} / \mathrm{m}^{2}$. The 

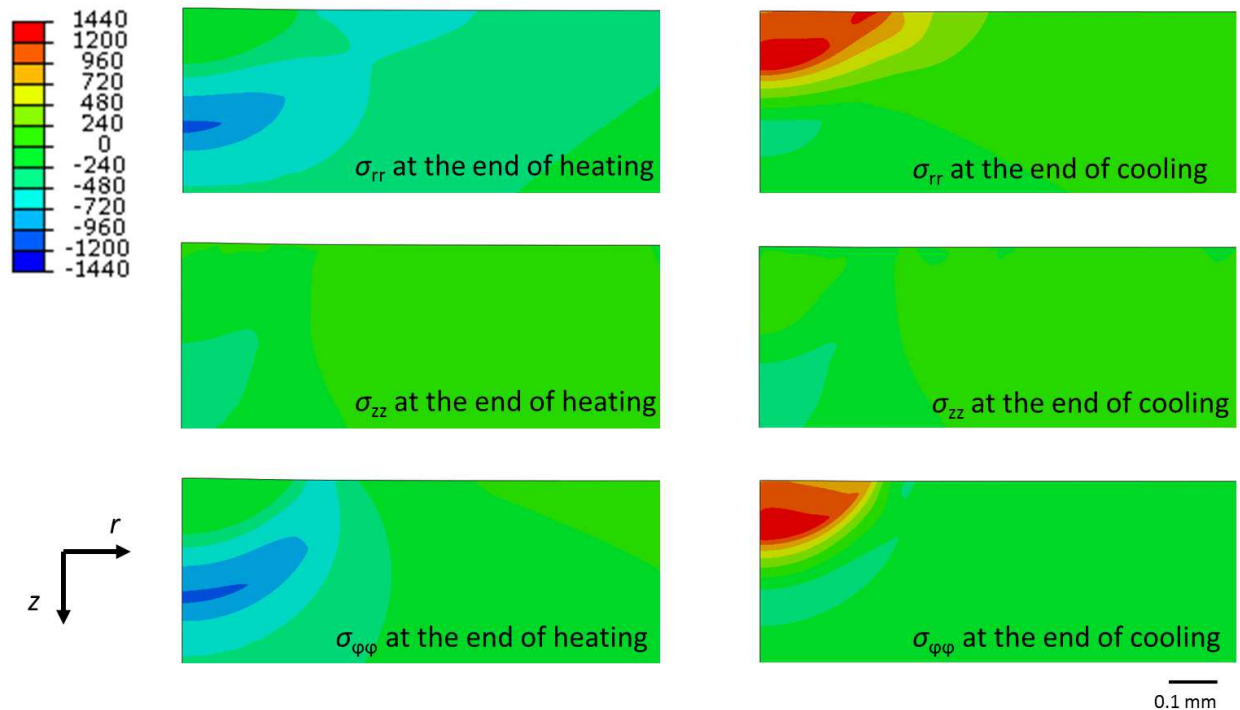

Fig. 18. Field of stress in radial direction for a thermal shock load of $0.624 \mathrm{GW} / \mathrm{m}^{2}$ (tension positive, compression negative). $\sigma_{r r}$, $\sigma_{z z}$ and $\sigma_{\varphi \varphi}$ are the stresses in radial, axial and hoop directions.

reason may lie in the fact that the surface roughening caused by a thermal shock load of $0.624 \mathrm{GW} / \mathrm{m}^{2}$ may result in a reduction of reflected electrons.

The cracking occurrence found in the experiments generally coincides with both the XFEM and the $J$-integral predictions. No cracking occurrence is found for a thermal shock load of $0.374 \mathrm{GW} / \mathrm{m}^{2}$, while for a thermal shock load $0.624 \mathrm{GW} / \mathrm{m}^{2}$ cracks are both predicted numerically and detected in the experiments. For a thermal shock load of $0.5 \mathrm{GW} / \mathrm{m}^{2}$, the experiments show an occurrence of tiny cracks. XFEM simulation predicts the initiation of multiple cracks, but these cracks are not completely opened. The $J$-integral for the precrack, which is situated in the central part of the loaded area and which is longer than $16 \mu \mathrm{m}$, is larger than $J_{\mathrm{c}}$ for a thermal shock load of $0.5 \mathrm{GW} / \mathrm{m}^{2}$. The numerical results for a thermal shock load of $0.5 \mathrm{GW} / \mathrm{m}^{2}$ indicate that cracks may occur, however, they do not grow as readily as for a thermal shock load $0.624 \mathrm{GW} / \mathrm{m}^{2}$.

\subsection{Surface roughness}

Line surface roughness results were extracted from Figs. 2, 3 and 4. Their results are shown in Fig. 29. Two lines (see the dashed lines in Figs. 2, 3 and 4), which pass through the center of the loaded area and are parallel to either the horizontal (width) or the vertical (height) edges of the LSM images, are chosen for the line surface roughness measurements. The roughness far away from the loaded area is assumed as zero. For thermal shock loads of $0.374 \mathrm{GW} / \mathrm{m}^{2}$ and $0.5 \mathrm{GW} / \mathrm{m}^{2}$, the roughness along the two lines does not exhibit dramatic local fluctuations, and surface roughening is induced by plastic deformation. For a thermal shock load of $0.624 \mathrm{GW} / \mathrm{m}^{2}$, the zig-zag profile of roughness suggests that cracks are opened.

The roughness predicted by the thermo-mechanical simulations is plotted as well. The roughness in the simulation refers to the vertical displacement at the top surface. In these simulations, no cracks are considered. The findings of the experiments and the simulation results coincide with each other for the thermal loads under which surface roughening is mainly induced by plastic deformation, and the minor error between the experimental and simulation results might 


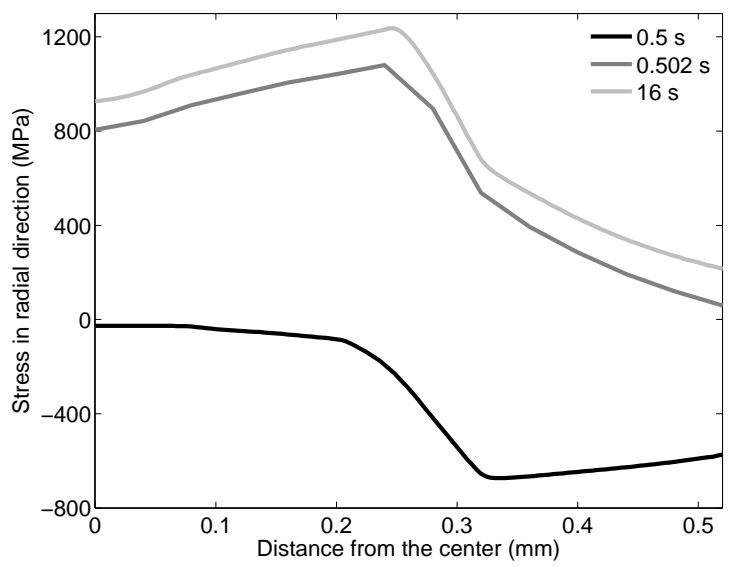

Fig. 19. Surface stress in radial direction at various times for a thermal shock load of $0.624 \mathrm{GW} / \mathrm{m}^{2}$.

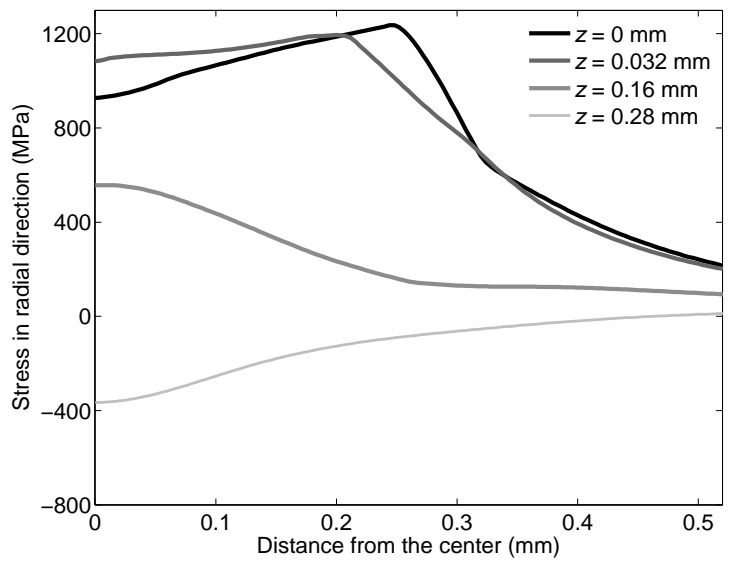

Fig. 20. Stress in radial direction at different depths at the end of cooling for a thermal shock load of $0.624 \mathrm{GW} / \mathrm{m}^{2}$.

result from the error in the thermal calculation and from errors due to the simplification of the model (e.g. circular instead of rectangular loaded area). If cracks are opened, there are obvious differences between the experimental and the simulation results, see Fig. 29 c. 


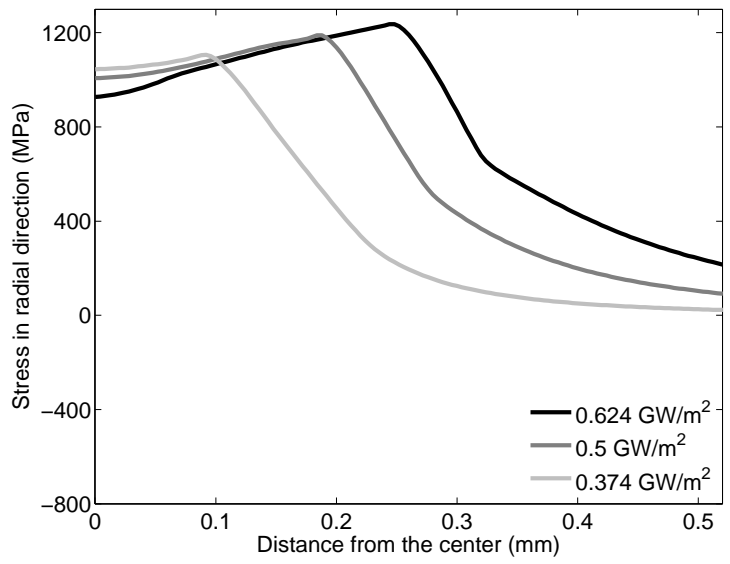

Fig. 21. Surface stress in radial direction at the end of cooling for thermal shock loads of different power densities.

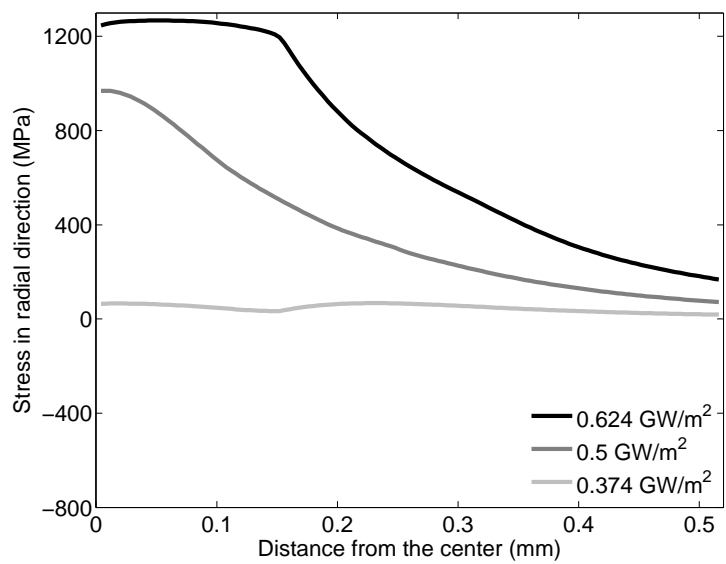

Fig. 22. Stress in radial direction at a depth of $0.08 \mathrm{~mm}$ at the end of cooling for thermal shock loads of different power densities.

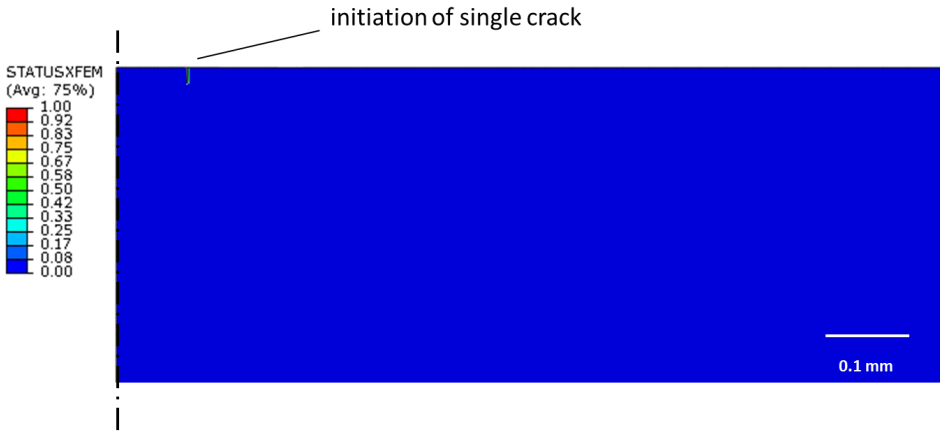

Fig. 23. Crack predicted by XFEM simulation for a thermal shock load of $0.374 \mathrm{GW} / \mathrm{m}^{2}$. 


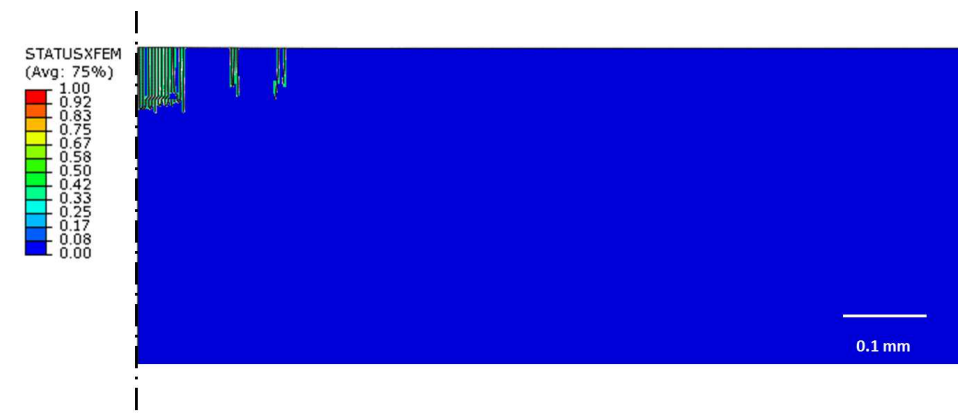

Fig. 24. Cracks predicted by XFEM simulation for a thermal shock load of $0.5 \mathrm{GW} / \mathrm{m}^{2}$.

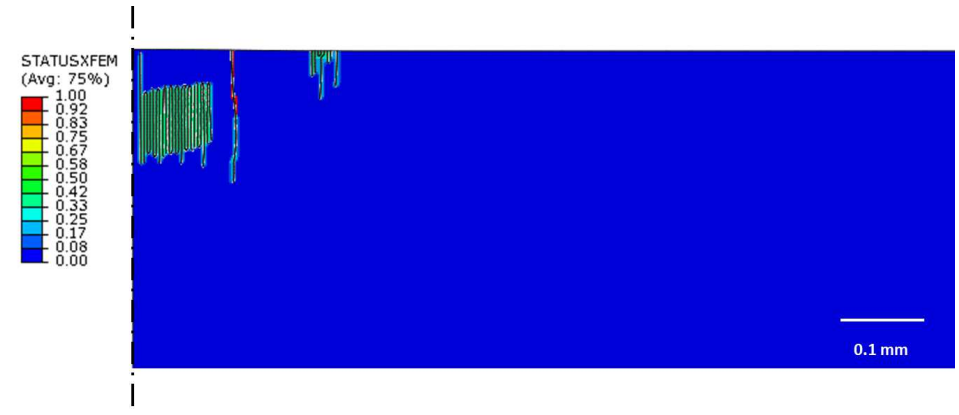

Fig. 25. Cracks predicted by XFEM simulation for a thermal shock load of $0.624 \mathrm{GW} / \mathrm{m}^{2}$.

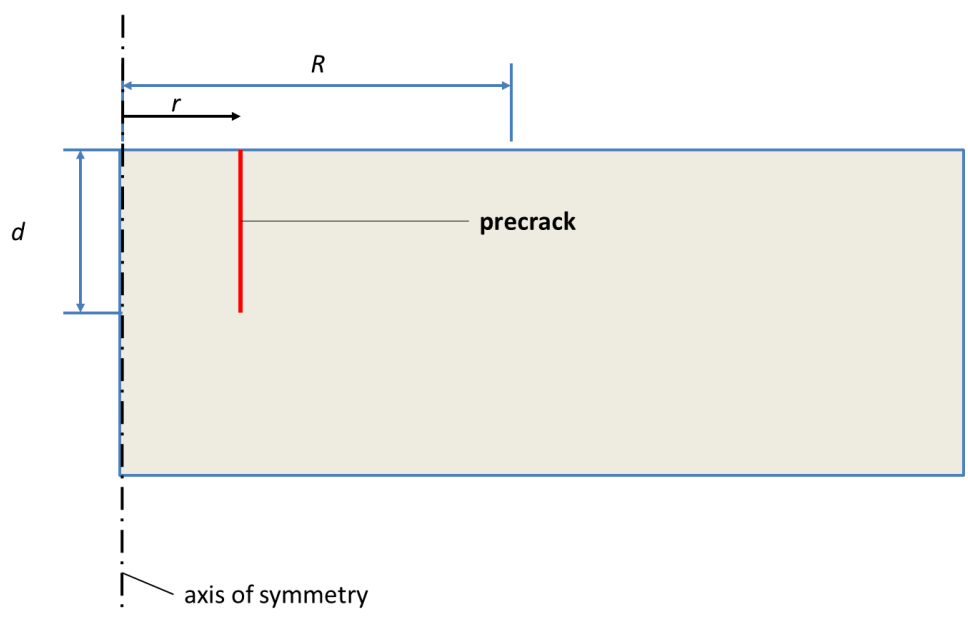

Fig. 26. Precrack for the calculation of the $J$-integral, $r$ is the distance from the axis of symmetry, $d$ is the length of the precrack, and $R$ is the radius of the loaded area. 


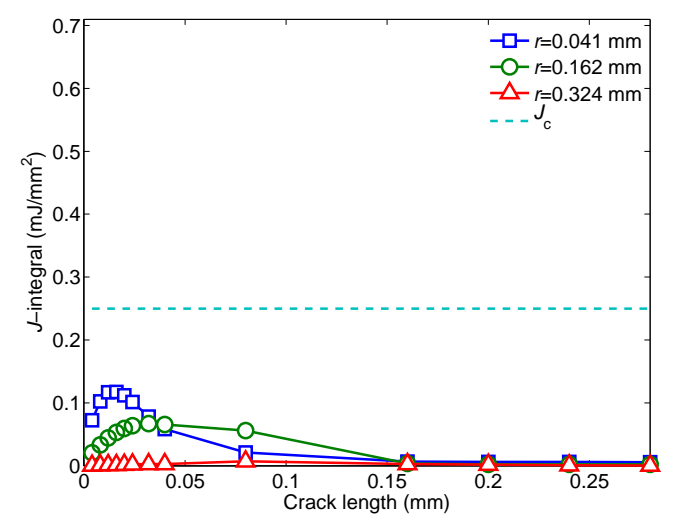

(a) $0.374 \mathrm{GW} / \mathrm{m}^{2}$

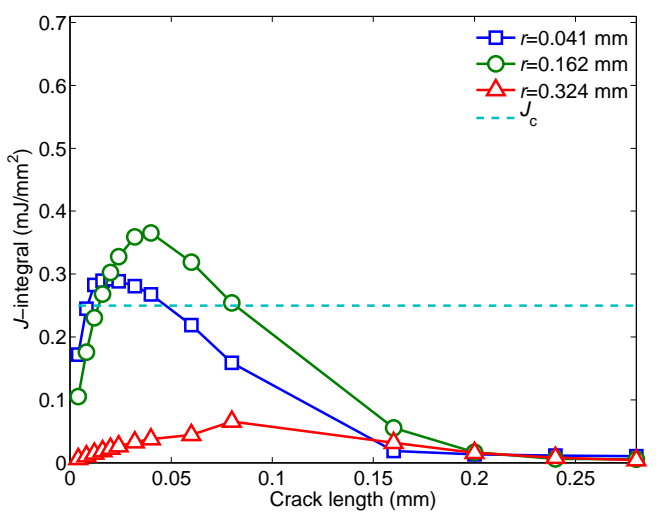

(b) $0.5 \mathrm{GW} / \mathrm{m}^{2}$

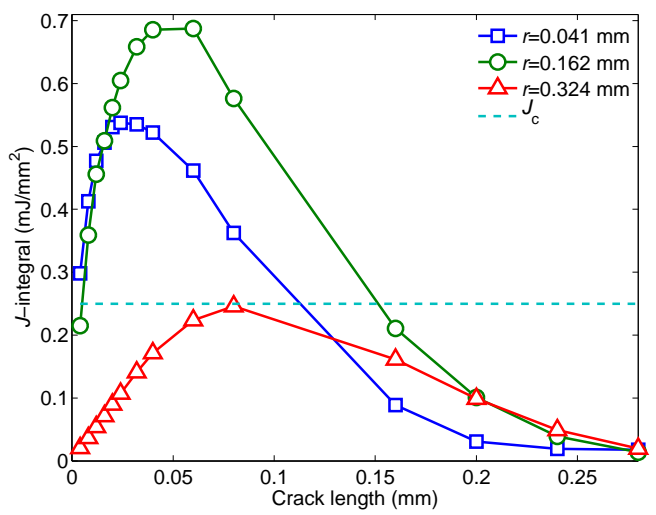

(c) $0.624 \mathrm{GW} / \mathrm{m}^{2}$

Fig. 27. $J$-integral for precracks at different locations as a function of the precrack length for thermal loads of $0.374 \mathrm{GW} / \mathrm{m}^{2}$, $0.5 \mathrm{GW} / \mathrm{m}^{2}$ and $0.624 \mathrm{GW} / \mathrm{m}^{2}$.

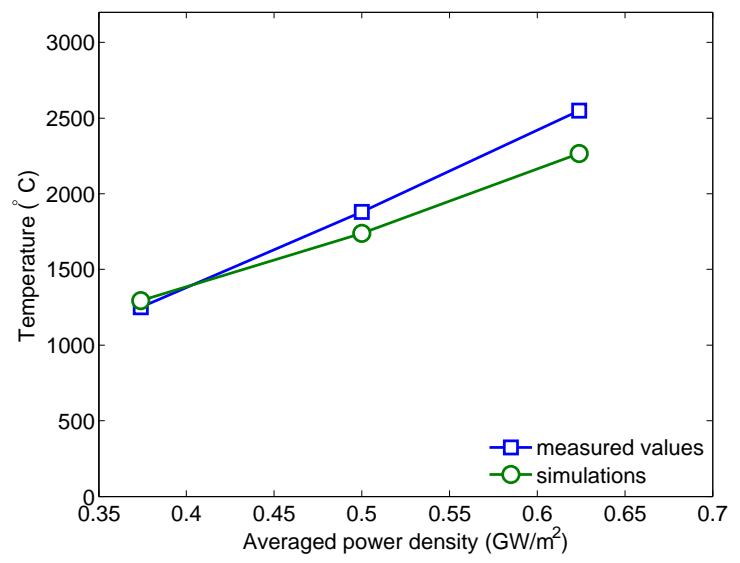

Fig. 28. Comparison of maximum temperatures measured in the experiments and calculated in the corresponding simulation for thermal shock loads of different power densities. 


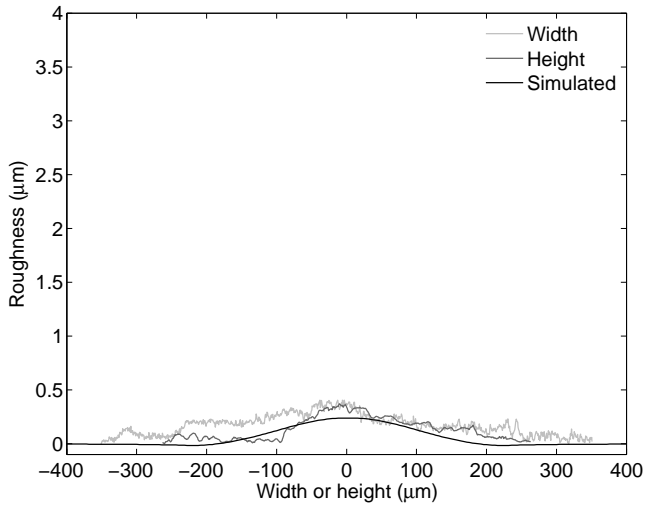

(a) $0.374 \mathrm{GW} / \mathrm{m}^{2}$

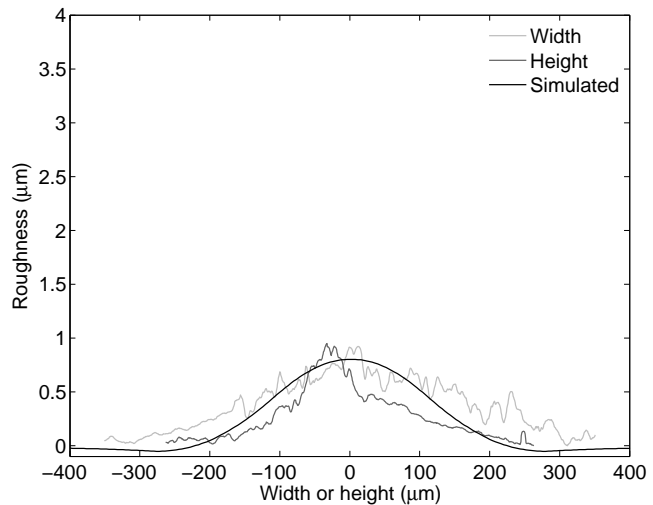

(b) $0.5 \mathrm{GW} / \mathrm{m}^{2}$

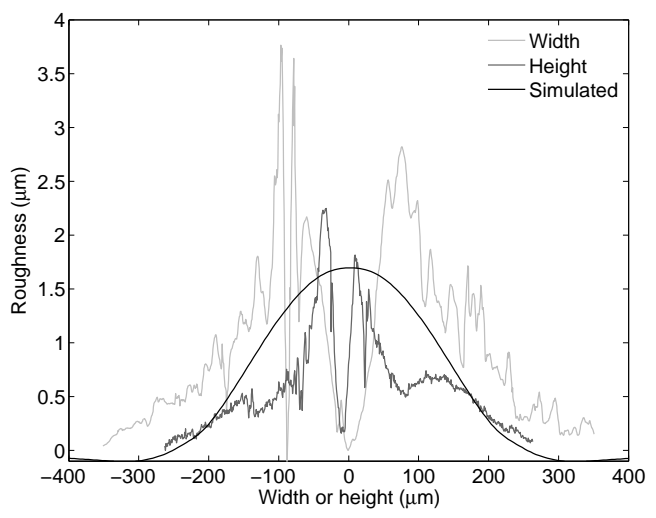

(c) $0.624 \mathrm{GW} / \mathrm{m}^{2}$

Fig. 29. Roughness for thermal shock loads of $0.374 \mathrm{GW} / \mathrm{m}^{2}, 0.5 \mathrm{GW} / \mathrm{m}^{2}$ and $0.624 \mathrm{GW} / \mathrm{m}^{2}$. Height: measured roughness along the horizontal dashed lines in Figs. 2, 3 and 4, Width: measured roughness along the vertical dashed line in the same figures, Simulated: surface vertical displacement in the simulations. 


\section{Conclusions}

In this contribution damage behavior of tungsten under high heat flux thermal shock loads was investigated assuming a single heat pulse with duration of $0.5 \mathrm{~s}$. Cracking mechanism was identified by means of FEM-based computational fracture mechanics analysis. The numerically predicted cracking features were compared with the experimental measurement obtained from the high energy electron beam irradiation tests. The followings are the major results:

1. Finite element simulations revealed that the thermal steady state was reached within several milliseconds after the onset of a heat flux pulse. Experimental observation showed that thermal shock loads could cause considerable grain growth, although the pulse duration was relatively short $(0.5 \mathrm{~s})$.

2. Finite element simulations confirmed that the surface cracking of tungsten was caused by tensile residual stress produced during cooling stage as a consequence of compressive plastic yield of the surface layer under heating.

3. At thermal shock loads below $0.5 \mathrm{GW} / \mathrm{m}^{2}$ the loaded area at the surface exhibited plastic roughening without occurrence of cracks. The plastic deformation of the surface layer was measured using the laser scanning microscope and compared with the predicted profile of the finite element simulations achieving good agreement.

4. According to the thermal shock tests open cracks began to form on the surface when the applied heat flux load was higher than $0.5 \mathrm{GW} / \mathrm{m}^{2}$. This threshold value of power density for cracking was predicted by the computational fracture simulation as well. Both XFEM technique and VCE method yielded consistent predictions on the cracking behavior.

\section{Acknowledgement}

The authors are grateful to Mr. Thomas Arnold of Siemens Healthcare, Germany, for his support with the experiments.

\section{References}

[1] N. Baluc, Assessment report on W, Final report on EFDA task TW1-TTMA-002 Deliverable 5, 2002.

[2] J. Linke, P. Lorenzetto, P. Majerus, M. Merola, D. Pitzer, M. Roedig, EU development of high heat flux components, Fusion Science and Technology 47 (2005) 678-685.

[3] A. Oppelt, Imaging Systems for Medical Diagnostics: Fundamentals, Technical Solutions and Applications for Systems Applying Ionizing Radiation, Nuclear Magnetic Resonance and Ultrasound, 2nd Edition, John Wiley \& Sons, 2011.

[4] G. P. Sutton, O. Biblarz, Rocket Propulsion Elements, seventh Edition, John Wiley \& Sons, 2001.

[5] J. You, H. Bolt, Analysis of singular interface stresses in dissimilar material joints for plasma facing components, Journal of Nuclear Materials 299 (2001) 1-8.

[6] T. Hirai, G. Pintsuk, J. Linke, M. Batilliot, Cracking failure study of ITER-reference tungsten grade under single pulse thermal shock loads at elevated temperatures, Journal of Nuclear Materials 390-391 (2009) 751-754.

[7] G. Pintsuk, A. Prokhodtseva, I. Uytdenhouwen, Thermal shock characterization of tungsten deformed in two orthogonal directions, Journal of Nuclear Materials 417 (2011) 481-486.

[8] J. Linke, T. Loewenhoff, V. Massaut, G. Pintsuk, G. Ritz, M. Roedig, A. Schmidt, C. Thomser, I. Uytdenhouwen, V. Vasechko, M. Wirtz, Performance of different tungsten grades under transient thermal loads, Nuclear Fusion 51 (2011) 073017.

[9] M. Wirtz, J. Linke, G. Pintsuk, L. Singheiser, I. Uytdenhouwen, Comparison of the thermal shock performance of different tungsten grades and the influence of microstructure on the damage behaviour, Physica Scripta T145 (2011) 014058.

[10] D. Rupp, S. M. Weygand, Loading rate dependence of the fracture toughness of polycrystalline tungsten, Journal of Nuclear Materials 417 (2011) 477-480.

[11] B. Gludovatz, S. Wurster, A. Hoffmann, R. Pippan, Fracture toughness of polycrystalline tungsten alloys, International Journal of Refractory Metals and Hard Materials 28 (2010) 674-678.

[12] J. You, I. Komarova, Probabilistic failure analysis of a water-cooled tungsten divertor: Impact of embrittlement, Journal of Nuclear Materials 375 (2008) 283-289.

[13] M. Li, E. Werner, J.-H. You, Fracture mechanical analysis of tungsten armor failure of a water-cooled divertor target, Fusion Engineering and Design 89 (2014) 2716 - 2725.

[14] G. Pintsuk, D. Blagoeva, J. Opschoor, Thermal shock behavior of tungsten based alloys manufactured via powder injection molding, Journal of Nuclear Materials 442 (2013) S282 - S286. 
[15] E. Lassner, W. D. Schubert, Tungsten: Properties, Chemistry, Technology of the Elements, Alloys, and Chemical Compounds, Springer Verlag GmbH, 1999.

[16] Abaqus analysis user's manual 6.12., Dassault Systémes Simulia Corp., Providence, RI, USA, 2012.

[17] PLANSEE, Tungsten material properties and applications, http://www.plansee.com/en/Materials-Tungsten-403.htm (2014).

[18] Siemens internal report on physical parameters of tungsten, Tech. rep., Siemens (1995).

[19] H. S. Carslaw, J. C. Jaeger, Conduction Of Heat In Solids, 2nd Edition, Oxford University Press, New York, 1959.

[20] J. R. Rice, A path independent integral and approximate analysis of strain concentration by notches and cracks, Journal of Applied Mechanics 35 (1968) 379-386.

[21] Y. Lei, N. P. O’Dowd, G. A. Webester, Fracture mechanics analysis of a crack in a residual stress field, International Journal of Fracture 106 (2000) 195-216. 